
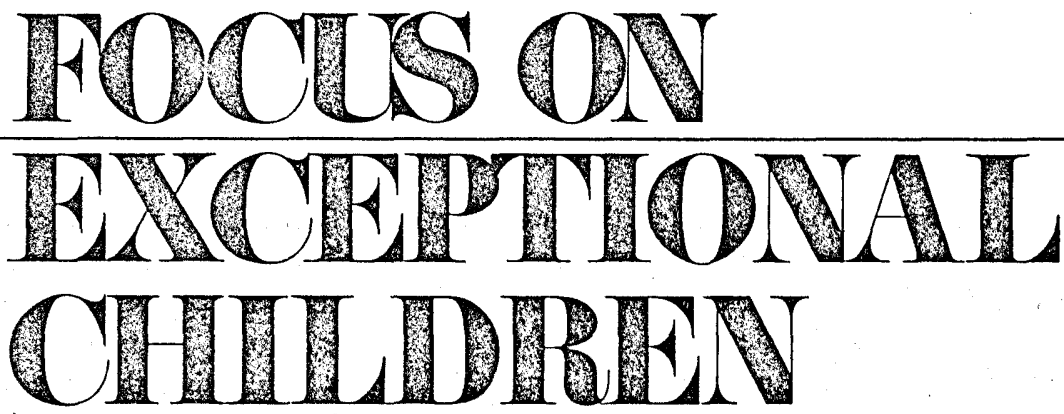

\title{
THE SEVERELY RETARDED: ARE WE REALLY PROGRAMMING FOR THEIR FUTURE?
}

FUTURE PROGRAMS FOR THE SEVERELY RETARDED
James R. Lent ${ }^{1}$

\begin{abstract}
Who you are today is a result of who you were yesterday .... and how you, your children, and grandchildren, and all children to come will live in the future will probably be a result of what you and I are doing today. (Barnes, 1974)
\end{abstract}

The children of the future of utmost concern in this context are the mentally retarded. What are we doing for them today? Are we aware that we are determining their future-a future which will have to be understood, underwritten, and managed by the normal children of today? Further, are we conscious that our daily decisions either conserve or change the course of society's future in terms of the quality of life for all persons?

\section{Foretelling the Future}

As many writers and that new breed we are beginning to label "futurists" have repeatedly told us during this last decade, we, as a society, have yet to face up to the absolute fact that we have entered a new age. There are many names for our emergent age, but for our purposes Barnes' (1974) label, the Post-Industrial Age, is quite suitable. Drucker $(1969,1974)$, in highlighting the characteristics of the times, points out over and over again that, while all elements of society are far behind in awareness of consequences of change as well as coping abilities, education is farthest behind. The predominant characteristic of the times is our complete institutional and individual interdependenceand yet education per se remains aloof from adjustment to interdependence, even from the ecumenical notions which institutionalized religion has partially accepted.

While it is obvious that science and industry have been the beneficiaries of education, all our articulate futurists have continually stated that education has not benefited from the survival discoveries of the other less mystically endowed disciplines. Private enterprise, in theory and in fact, exists only as it subcontracts its existence from public

1. Dr. Lent is Director of Project MORE (Bureau of Research, University of Kansas), Parsons, Kansas. 
enterprise. As Drucker (1969) illustrates this, even the Department of Defense finds its subsistence through the support of its "private" suppliers. Expertise is, after all, hard to come by in a world where the entire body of knowledge doubles upon itself in six months' time. The experts are the ones who know how to find-perhaps invent or enable the development of-answers and solutions. They are managers. They are persons who understand the technology at hand, and also they are persons capable of continual learning. They keep up. They recognize that change is their only absolute, and they know that they must not only be amenable to it but even anticipatory of it.

\section{Education Doesn't Learn}

Education, on the other hand, still relies on the patterns the Don system established in the years shortly following the Gutenberg press. The person who owned the book was paid to read from it to the assembled students. (In fact, the word "lecture" originally meant a reading!) How far has education come? Has it been forced to adapt? How does it accommodate change? And, skipping over a great many other pertinent though rhetorical questions, how does it account for itself when human priorities and their concomittant cost factors are the basics for our new age?

Education, tranditionally thought of as a hierarchical process, must become consumer-oriented. The successful "enterprises" of today-whether we insist on the labels public or private is of no consequence in an interdependent

FOCUS ON EXCEPTIONAL CHILDREN is published monthly except June, July, and August as a service to those concerned with mentally retarded and emotionally disturbed children. This journal is abstracted and indexed in Exceptional Child Education Abstracts. Subscription rates, $\$ 9.50$ per year. Copyright 1975, Love Publishing Company. All rights reserved. Reproduction in whole or part without written permission is prohibited. Printed in the United States of America. Second class postage is paid at Denver, Colorado.

$$
\begin{gathered}
\text { Executive and Editorial Office } \\
6635 \text { East Villanova Place } \\
\text { Denver, Colorado } 80222 \\
\text { Telephone (303) } 757-2579
\end{gathered}
$$

\section{EDITORIAL BOARD}

Edward L. Meyen University of Kansas
Glenn A. Vergason Georgia State University

Richard J. Whelan

University of Kansas Medical Center
Sallie Carmachel Keeney Managing Editor
Stanley F. Love Publisher
Post-Industrial Age-already predict those of the future: They all consider marketing as their "crucial task" (Drucker, 1974). Education is our sole "enterprise" which is rooted in two age-old prejudices: the Puritan ethic, which insists that the learner can be "wrong"; and what Drucker calls the traditional European social prejudice against market, customer, and selling, which says that, in effect, the teacher and the school are "noble" and the client who must be able to respond to them according to rule should be grateful for the chance to do so. These two belief systems combine to make what seems to be an insurmountable resistance to the need for new alternatives and, indeed, for the notion that accountability to the consumer must determine these alternatives.

\section{Technology Is ...}

There are some who would argue and divert the issue with a great deal of prattle about "educational technology." They would insist that they have become acquisitors and managers of hardware which individualizes, equalizes, and maximizes learning. I would agree with that part of their argument which claims that we do, indeed, have these tools at hand. But, as Drucker (1969) states, technology is not only the presence of ready tools and the technical understanding of their utility, but also the organization for their effective and efficient work. The human, value-judgment input-the software, if you pleaseis the other element in the compound we call educational technology.

Today, the appropriate software is largely unavailable. This means that, with rare exceptions, we simply do not have an "educational technology." Especially, we do not have one working for the handicapped.

The question that the entire field of education, not just special education, evades is, How does one go about creating this software? This is a terribly difficult question; it comprises the crux of what we are describing as "educational technology" for the purpose of any technology is to multiply the effects of human expertise-to make "an ordinary person capable of extraordinary performance"' (Drucker, 1969).

Since we are already aware that we cannot possibly train enough teachers to handle even our present educational load (Commission on Instructional Technology, 1970)-in the traditional training mode in which the teacher is considered to be the "expert" who can process all possible inputs into learning bits-the primary task for 
educational technology is to train others to teach. We must train-to-train.

It is quite important to realize that there are paradigms for this enormous task. Again, science and industry have led the way. Many examples might be cited; instead, it must suffice here to mention a basic commonage that these examples have. When industry trains a skill, it narrows an instructional objective into a carefully sequenced and mediated format which systematically enables learner success. $^{2}$ It has made skill acquisition an effective and efficient proposition. It has done so because it must do so, because it is accountable in the marketplace.

\section{There Is MORE}

This is, in brief, the paradigm for education. And, indeed, there are some few models already developing in the field of education, although not without difficulty and incomplete facilitation. One of these models for the emergent and absolutely necessary technology, I am proud to say, is Project MORE.

Project MORE is systems-oriented and systemsmonitored. The acronymn stands for Mediated Operational Research for Education-and we hope these words indicate the technology we have developed and refined during the last several years. We believe that our technology for design, development, and dissemination of daily-living skills programs for the trainable-level retarded assures the exportability of our programs--even when these programs are used by unskilled trainers.

We begin with an implementation procedure which requires that we consider market factors, along with other feasibility factors, before any other preliminary design stage on a projected program. Personnel from various complementary disciplines-dissemination, educational research, mediation, and systems management-carefully analyze need and feasibility. We use an implementation "lattice" (Figure 1), and each box on this diagram signals a task to be completed before another task can be begun.

We conduct a market survey and a literature search in the process of deciding whether to invest staff time and Project funds in developing a program. We do not "reinvent the wheel." If some other developer had produced a validated program for training the severely

2. See Drucker $(1969,1974)$ and Butler (1972) for details and examples. Also, the works of Marshall McLuhan, R. Buckminster Fuller, and Robert F. Mager are both interesting and helpful in this context. retarded in appropriate eating skills, for instance, there would have been no Project MORE Eating program.

Next, we conduct a careful task analysis on a normal population performing the necessary skills which would comprise the program steps. This analysis is then compared with one conducted on our target population-the trainable retarded. The data are compared, and the resultant findings are used in sequencing the steps and detailing the behaviors in the writing of the program.

At this point in the implementation procedure, the entire developmental process for the program is "loaded out" or projected in some detail on a chart which specifies personnel time, machine time, and other cost factors. Sometimes this loading process causes us to stop work on a program. Once, we found that a program, though badly needed by our consumer population, would require 32 months of Project development time. Of course, we could not proceed with it; it is necessary for us, like many other federally funded developers, to successfully complete a number of products each funding year. We must maintain a credibility level as an applied research group which actually manages to produce. We, and the other developers of validated products for the handicapped, recognize the legitimate federal concern with projects who spend all their time "researching" and never actually delivering to the intended consumer (Comptroller General, 1973).

Once a "go" decision has been made on feasibility factors, a teaching strategy is imposed upon the step-bystep sequencing of behaviors which the task analyses have disclosed. The strategy is designed to enable the trainer who will use the program to train the pupil to perform the program steps absolutely independently.

Specific formats and other mediational factorsincluding language level and style for the trainer's use-are determined at this point. Then, a prototypical program is produced for the researchers' use in field testing on the target population. Each program has its own checklist for the trainer to use in keeping data on each student's performance. The trainer, who is a nonstaff, nonprofessional person employed part-time for the field testing process, is also given graph forms which are used to display the student-acquisition data for each program. As an important aside, the Project is discovering that studentproficiency charting and graphing does not interfere with the training process but enhances it.

Data must, of course, prove a program valid before it enters the final mediation stages on our implementation lattice. Sometimes, to be sure, a program must be revised 
Figure 1

IMPLEMENTATION LATTICE

D

c
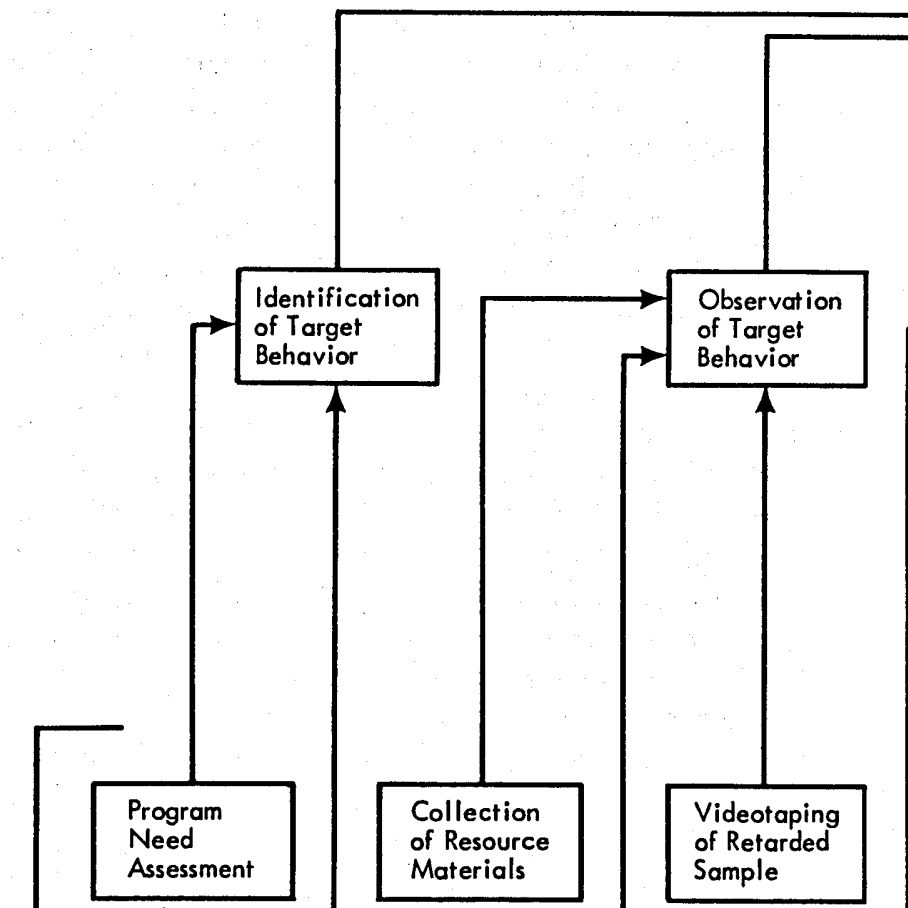
Identification of Target Observation of Target

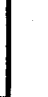
1 \begin{tabular}{|l|}
\hline \\
\hline Videotaping \\
of Nonretarded \\
Sample
\end{tabular}

Preliminary Feasibility Assessment Behavior 2 4

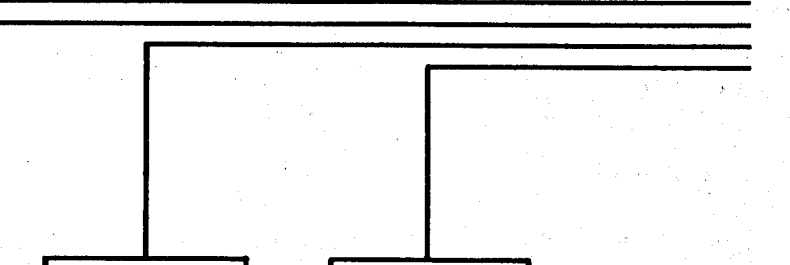

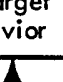
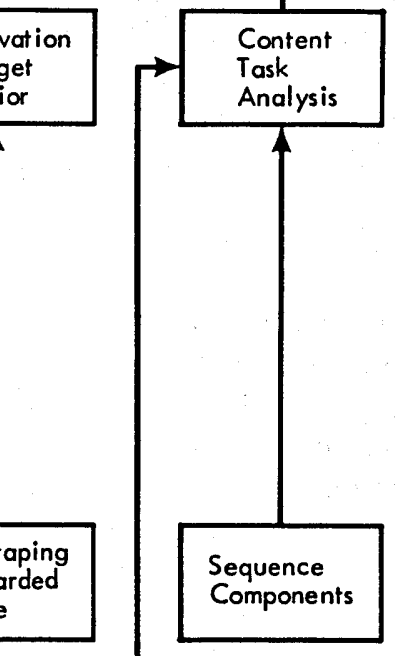

7

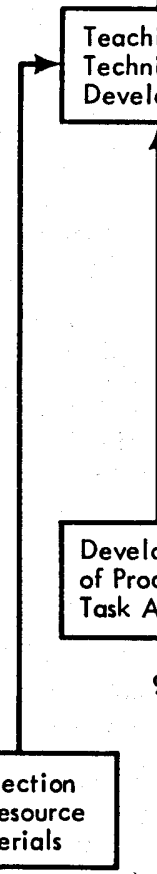

8

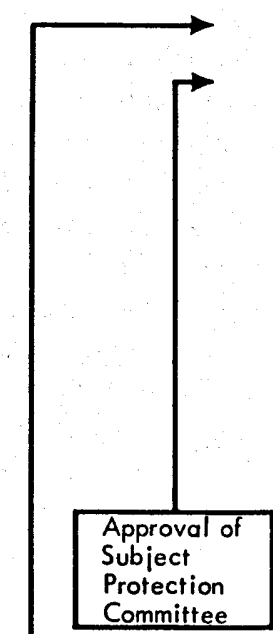

11

The above is a partial illustration of Project MORE's Implementation Lattice 
so extensively, according to field-test results, that it must be recycled through the prototype-development stages. In no case is a program released to the publisher without adequate validation data from field testing. Project MORE's major new thrust must be adequate retrieval and use of market data-data from the primary consumer, the trainer, as well as data from the secondary consumer, the handicapped learner.

A very good explanation of this basic concern that we believe developers of educational materials must all adhere to appears in EPIEGRAM (1975):

Learner verification and revision does not mean "scientific studies," involving large national or statewide samples, experimental controls, and scientifically valid proceduresall coordinated by high-priced, independent (for credibility) evaluation agencies.

Learner verification simply means developing-and revisinga product with primary concern for its instructional effectiveness-and ascertaining that effectiveness by the simple, empirical means of USING FEEDBACK FROM $L E A R N E R S$. Thus, on the surface, a learner verified and revised product will not look much different from any other instructional product-but the story of its development and continuing revision will be unique.

The product developer would be committed to systematically gathering data about the way students are learning, and are failing to learn, from the material. That data would not be in the form of generalities, or mean average scores; it would be very specific, fine-grained data-that would pinpoint precisely which parts of the material were causing problems for learners. With this data, the developers would know exactly which segments of a filmstrip were not working; what chapters, pages or illustrations in a textbook were causing instructional problems; which portion of a TV series was obscure. The developer would have identified the specific sequences, sentences, illustrations, and even words that were keeping learners from absorbing what the material was intended to help them learn.

This data would not just be gathered-it would be used to improve the product's effectiveness. The data would show where-and what-changes must be made to eliminate problems learners encountered with the materials. The changes might be as small as rewording a misleading instruction or replacing a confusing illustration with a clear one.

An extremely important aspect of our development process is our continual dialogue with our publisher, Edmark Associates (Bellevue, Washington). Not only are specifications for media formats on programs and supplementary or auxilliary materials agreed upon by the Project and the Publisher, but also personnel representing the Publisher receive training on the programs' objectives, strategies, and utility. All marketing is conducted by trained personnel-and most of it is joint-effort enterprise utilizing project personnel and Publisher representatives.

One of our most definitive efforts in this kind of dissemination is an inservice workshop for teachers of the retarded as well as parents and paraprofessionals who are presently faced with the implementation of the courtmandated habilitation and education of all citizens. Because of these proliferate mandates, it might seem that our Publisher has a mass-market potential, rather than the thin-market usually anticipated for special education materials. The Publisher and the Project have had to work diligently to create a market, however, for the daily-living skills programs. The marketplace still, it seems, does not understand that equality of education or treatment does not necessarily require that the standard curriculum offerings of the Industrial Age (the "three Rs," we might say) must be learned in some watered-down way by the severely retarded. Project MORE ascribes to the notion of equity for the severely retarded, so that they may be afforded the chance to re-enter community life with as much dignity and productivity as possible.

For our purposes here, I believe that I should not devote more space to exposition regarding Project MORE's work, however tempting a continuing discussion might be. Rather, I believe that I should take my personal convictions which have spawned the development of the Project and apply them to the field of special education in general-and to the training of the severely retarded in particular.

\section{THE VIEW FROM THE FIELD}

If one were to view today's practices as predictive of tomorrow's shape and style, the vision would be very depressing. The field of special education is not reacting to the problems of yesterday and today. It is merely coping. Some of the practices are concrete, some semi-solid, and others fluid; but if these are continued indefinitely, they guarantee that in 25 years the field will be a hopeless anachronism rather than "just behind." It helps to remember that the shape of the future is in our hands and that we are not bystanders but participants. It helps to remember that there are alternative futures. It may be useful at this point to review some of our current practices in order to gain perspective about their influence on the future.

The most important development since the end of World War II is unquestionably the Right to Education movement. It must be seen as a reactive event. It is not 
proactive. $^{3}$ It will not in and of itself bring about a more enlightened future for the disadvantaged. The movement is a reaction against cultural lag, mishandling, and inattention. As cultural analogs we have other specific thrusts of the civil rights movement, and these seem to be succeeding, though slowly. It is dangerous, however, to use other areas of the civil rights movement as predictive analogs. The gains that have been achieved in human rights are not due to belated though enlightened legislation alone. They are due to the creativity and stubbornness of disadvantaged blacks and other minority groups themselves. They have followed up in establishing relevant civil-action precedents. They have persevered, and in so doing they have actively shaped the implementation of civil rights practices.

What if-just what if-they lacked the ability and desire to play such a proactive role? Suppose that the future of the civil rights movement was left in the hands of others-bureaucrats, school administrators, college professors, school teachers. Unthinkable. I wonder, then, if the Right to Education movement really can change things. Certainly it cannot provide its own leadership or organizational impetus. It must rely on advocates-and most of these are only morally obligated to be concerned with the rights of the disadvantaged.

\section{Our Role Determines Their Fate}

The fate of the movement is in our hands. The tools which legislation and civil action have provided us can be used to serve the representatives of the movement in the name of the "cause"-not willfully, of course, but because there is not a built-in corrective mechanism, the voice of the retarded.

In our necessary role as advocates, we must be wary of the changes that are beginning to take place: Are they real or cosmetic? Are they proactive and future-oriented or merely convulsive reactions? First of all, at the time of this writing more than 37 states have either enacted legislation or handed down civil court decisions which mandate that all children, regardless of ability or handicapping condition, receive the benefits of a public school education (Lippman \& Goldberg, 1973). This is both overdue and commendable.

But, now that these new handicapped citizens are in the schools, what in the name of Dewey will we do with them?

3. Reactive and proactive are descriptors for attitudes toward human problems as they affect the shaping of alternative futures in Barnes' writings.
Now that they are streaming out of the institutions into the communities, what will we do? I am not suggesting that it would have been better to leave well enough alone. I am suggesting that some of us most activate our roles as the creative, stubborn representatives of the voiceless and helpless.

\section{Their Role Must Be Reactive}

We must devise and operate a technology that will give the mentally retarded the skills which will allow them citizenry in the Post-Industrial Age. We do know that the retarded can only "get along" by successfully reacting to the world of the normal, and we know that the world of the normal will continue its rapid pace change. We know the forces at work to create change, and perhaps this knowledge will be sufficient to give us direction in our planning.

The most notable force for change is the knowledge explosion. Its shock waves create change, profound change. Merely to survive, the average man must acquire new skills and new patterns of behavior. Can we predict the role of the retarded in a future when we cannot yet accurately predict the role of the average man? The answer is no! Of course not! There is not one role cast for the new age person-because we have alternative futures.

However, some requirements for life in the future are going to be the same as in the present. For instance, the severely retarded will still be dependent upon normals in spite of any legislation or any technology. This means that they will be accepted or tolerated in this world because of skills they possess, not in spite of their deficits.

\section{DAILY-LIVING SKILLS AND THE CURRICULUM}

The skills required for acceptance, or toleration, are mostly social-especially in the case of the retarded. They must not offend and, if possible, they must please. Is this an "unfair" or inequitable rule? One applied only to the disadvantaged? Not really. The application of the rule varies in degree only. With "normals" it is often possible to be tolerated or even sought after in spite of deviant, offensive behavior. This is because the nonretarded person is far more likely to have sought after or required skills, compensatory skills. This is not the case with retarded persons. Not now, and especially not in the future-any. future. 
Skills required for any future also resemble those required for adjustment to the community today. The most notable categories, although not recognized by many educators as legitimate major parts of a curriculum, are personal appearance, personal hygiene, and contributive use of leisure time. Use of leisure time will assume increasing importance in any world of the future-and not just for the retarded. I wonder why educators have not made this area one of their research priorities.

It may sound as though I have not provided any really penetrating insights by simply listing these categories of skills. Perhaps not, but have we applied our on-hand technology to these categories?

- Identifying precisely the required responses

- Sequencing them for presentation

- Combining them with teaching strategies

- Putting the programs in usable packages

- Teaching them to retarded persons

- Verifying by data feedback that the retarded have acquired and can use the skills

Are we even intending to do these things?

\section{Placement in Schools}

A phenomenon to be considered by decision makers of today, and therefore tomorrow, is the placement of mentally retarded children in the public schools. There are two main practices today, and there is argument over which is more appropriate. First, there is the special class, the self-contained classroom. There are special classes for the educable, trainable, and the more severely retarded. The other argument is usually referred to as mainstreaming. Mainstreaming has a nice ring to it; besides that, it is new-or is it? Conley (1973) sheds an interesting light on the subject.

In 1968 and 1970 there were approximately $1,936,000$ and $1,975,000$ children who were 5 to 19 years of age with IQs below 70 . We have estimated that about 631,000 and 690,000 were in special education programs. On the basis of previously computed information, it is estimated that the number in institutional care is 108,000 in 1968 and 110,000 in 1970. This leaves about $1,197,000$ who must have been in regular academic classes or not in school in 1968, and $1,175,000$ in 1970 , a slight decrease.

Most retarded children who are not in special classes or in residential care attend regular academic classes. Of over 11,000 school-age children identified as mentally retarded in New Jersey in 1953, $41 \%$ were in special education classes, $49 \%$ were in regular classes, and only $10 \%$ were not attending school. In the 1970 survey of special education programs conducted by the National Center for Educational Statistics, an estimated $28 \%$ were attending regular classes on a full-time basis. Undoubtedly in both cases many more retarded children attended regular classes but were not identified as retarded.

In other words mainstreaming has been going on for years, right under our noses, too. This is not to say that mainstreaming is not a good idea, especially since later efforts have included a resource room to supplement the offerings of the regular class. At this point, however, it can only be regarded as another reactive measure-a reaction to the failure of special classes and the pressures from the Right to Education movement. I am frankly skeptical that the regular grades can do a good enough job, though they may do a better job for some children than the special classes.

The reason that I question the adequacy of the regular grades in educating the retarded is that $I$ think the public schools do not do a very good job with many "normals." Every year new thousands of young persons are pushed from the traditional processing of the public schools into a world that is too difficult and complex for their management. In regular education as well as special education, new teaching skills have not been brought to bear on old problems.

Since the public schools are failing with an incredibly large number of nonretarded pupils, I doubt that the simple expedient of regular class placement is going to help the retarded to the degree that is required. The resource room is a step in the right direction because it gives promise of prescriptive help. But the present state of the art is not sufficient, and many children will not be given specific community-required skills.

There are two main reasons for this. First, the community-required skills that were discussed previously are rarely taught in regular schools to a useful extent-even in resource rooms. Second, whatever is being taught is dependent upon the artfulness and dedication of available teachers. This means that a few lucky children will be helped while the rest will remain in trouble. Clearly what is required is a whole new system of education for the retarded. A system that teaches the most needed behaviors and that guarantees that each child demonstrates proficiency in the skills selected as priorities for that particular child. We need a system that will not accept the child's failure to learn as simply the child's fault. The system and the people in it will have to accept the blame for child failure. 


\section{THE SEVERELY RETARDED ARE SPECIAL}

In the case of the severely mentally retarded child (trainable and below) there is reason to discuss even further the issue of self-contained classrooms. It has not seemed feasible to consider this group of children eligible for mainstreaming. At the present time, under the present structure of public schools, this assumption is probably correct: They could not be integrated. This leaves us to consider the adequacy of the special classes that have been established for them in a variety of educational environments. In general, I think it is not possible to provide training in the typical self-contained classroom. Trainablelevel and other severely retarded children generally need even more individualized instruction than those designated as educable (who also need more than they get).

The mechanics of one teacher with 8.12 children will not allow for much individualized teaching. As a group, these children will have severe language deficits, both receptive and expressive. Therefore, teacher-talk/childrenlisten is even less effective. as a teaching mode than with other children. Because of this, it is difficult to teach children in groups-even small groups.

In addition, most of these children do not have enough reading facility to use self-instructional materials. These reasons combine to explain, in part, why it is so popular for teachers to try to teach concepts like "citizenship" rather than skills like stopping at stoplights. Teachers can talk to groups about citizenship and only be accountable for input, not output. After all, who can measure good citizenship acquisition? Who can say the teacher did not do a good job? It is also popular to teach some skills that teachers do understand and believe in, like reading, but which some children will not need as badly as they will more mundane things, like toothbrushing and replying appropriately to common greetings. All children in our society are better off if they can read, and many trainable children can learn to read. Contradictory? In the education of the retarded, we have to keep first things first; a skill such as responding appropriately to authority figures comes first-it is a survival skill. Therefore, reading is a second, not a first.

The problem is not simply that we lack knowledge concerning the teaching-learning process. At this point in time we have more knowledge than is being used. We have more than adequate data that the presence of children in school buildings does not guarantee learning. It is also useless to argue the merits of special class versus main- streaming where there is reason to suspect that both "solutions" are inadequate and inappropriate.

\section{Who Needs to Learn What?}

What steps would we take now to insure that more children will be prepared for any of our possible alternative futures? Barnes (1974) has made a very literate summary of the predictions of various futurist writers and concludes that there is at least one certain aspect of our future regardless of the many possible alternative modes it may assume. This is the need to learn-to-learn. This ability will be required because of the knowledge proliferation and resultant technological acceleration. Changes will occur too rapidly to allow for learning new skills in an apprentice-like fashion. Schools will have to teach learning-to-learn rather than specific job and knowledge areas. This picture of an even more complex and bewildering society requiring even more sophisticated survival skills does not bode well for any child of this generation, let alone the retarded and the failing normal. How are we going to learn-to-learn so that we can teach others? And, what about those who cannot learn-to-learn? Will there be a meaningful place in our society for those who are disadvantaged learners? Since I have written to this point for another purpose (Lent, 1975), I will answer with the following:

Our society is slowly moving to guarantee certain benefits to all citizens. This glacial move will eventually fix the lower limits of life style - of health and social welfare for all people regardless of their economic status or potential. As we move inexorably in this direction, it will force us to make a more careful definition of the meaning and nature of everyday life. It will probably be seen that work is not possible or desirable for all citizens and, additionally, that the nonproducers are entitled to a meaningful and satisfying existence.

Work and leisure, as concepts, will be thrown into sharp
focus. For those who have the means to use leisure in
creative and satisfying ways, there will be an option to work
less without social stigma. This, in turn, may mean that
there will be increased opportunities for work for those who
find it rewarding and fulfilling.

Automation will continue to decrease the need for unskilled work, but it will not eliminate the need for such services. There is likely to be less competition for such work in a society that provides other options. This could mean an increased opportunity for unskilled work for those who may find it satisfying and dignifying. This circumstance could be a direct benefit to the handicapped-who now find they are often in direct competition with normals for jobs that the normals don't really want.

As the use of leisure becomes more prominent as an issue, it will be studied in more intense and systematic ways. Leisure 
will assume the proportions of a full-scale social problem. We will find solutions to the problem in the same manner that we eventually find solutions to other social problems.

Against this background the problems of handicapped citizens will be seen as pressing but not unique. The things that they require to enjoy the quality of life are the same that millions of the disadvantaged have always required.

\section{Work Skills as Societal Need}

Some futurists predict that in a steady-state economy there will be widespread unemployment and welfare support without stigma. I believe, however, that ingrained in our value system is the idea that each person needs to have and exercise a work skill in order to be a respected member of a community; I believe that this idea will prevail, although the economics of enterprise in general may indeed change. It may be worthwhile, for instance, for business to subsidize sheltered workshop communities as European business is already doing. The point is again, we must be careful about our plans for work training for the retarded because what we do will determine their futureand our own.

In relation to jobs, I feel sure that the retarded can be competitive with others for certain required activities-if they are properly trained. This suggests that we must learn more rapid, efficient methods of training the retarded (and other disadvantaged groups) to perform a variety of work tasks which we know will change and change again. It is we, the advocates, who must learn to train-to-train.

The future that we predict for the retarded is the future that will come true. If we predict that they can learn, if only we know how to teach, then they will learn. If we predict that they can learn a wide variety of complex new age tasks that will allow them to take a real place in the world, then they will. There are already encouraging demonstrations that this kind of training/learning is possible. Gold (1968) is an example of the new age educator who is demonstrating that even the severely retarded can learn complex job skills if we learn how to teach.

Such an approach-one that is systematically concerned with what happens to make children learn-will require a new definition of the teacher's role if the job is to insure that each child receives a no-fail prescriptive education. The system itself must provide the technology if the teacher is to fulfill the newly defined role. These several interrelated issues will be discussed separately in greater detail.

\section{Solutions: Trainers and a Technology}

How can we arrange to present individualized, appropriate survival training to large numbers of trainable-level children? Obviously, it cannot be done the way we are now going about it. It calls for bold new approaches. The first of these is obviously to choose our teaching targets more carefully. This means to choose them with cost-benefit to the consumer as a guiding criterion.

The next thing is to arrange for more trainers-not teachers-trainers. It is possible for one professional-level person-teacher, if you like-to manage the activities of several nonprofessional but highly skilled trainers. These trainers-teacher-aides, if it is a more confortable term-can perform nearly all the functions of skill training required by the retarded if they are given adequate direction and functional teaching materials. The time required for training these trainers is significantly less and salaries will be noticeably less.

More trainers do not comprise a total solution. We need to rearrange the training/learning environment to allow for intensive individualized instruction and appropriate group activities to occur both simultaneously and sequentially. This calls for a recognition that no one teacher can do all things for all children-as in the self-contained, selfdefeating classroom model. There are many arrangements which would be an improvement over present practices, but the one that holds the most promise is an adaptation of the circuit training model. ${ }^{4}$ In this arrangement a variety of learning centers appropriate to different teaching targets are established. The centers are arranged in logical context to each other according to program content and developmental level of the learning task. For instance, in one room there may be a variety of learning stations at which several pairs of trainers and learners are concentrating on personal appearance and personal hygiene skills. Although many of the children may be relatively young, there is no stigma attached to older children receiving instruction in the same environment. This is a neat answer to, What do I do with an 18-year-old who hasn't learned to wash his hands? I can't treat him like a baby. Next to the intensive individual training room, there may be a group activity room for children who have earned credits (reinforcers) in skill training. In this space they may spend small periods of free time playing with games, with each other, or with the

4. Circuit training studies and models have dealt with physical education and motor development. The idea presented here was inspired by Del Turco (1971). 


\section{PRESENT}

Institutionalization

Make-or-break for the mentally retarded in the community

Traditional public school administrative structure

Special class placement by category of handicap

Traditional teacher training and certification through institutions of higher education

Quality and quantity of teaching dependent upon supply of gifted teachers

Federal funding by reaction to current and past problems

Production of tools (software/hardware) by selfinitiated process

Instructional materials (and media) bought on basis of assumed or perceived worth or teacher familiarity

Research in learning theory and teaching techniques for the sake of further research and for dissemination among colleagues only

\section{POSSIBLE FUTURE}

\section{Prevention}

Appropriate community role

A continuum of living/working arrangements with lifetime availability of training and support

Management by systems techniques for student behavior change on cost-effective basis

Learning centers for all persons with similar learning problems and similar behavior deficits

Training of managers of teaching/learning environments and training of paraprofessionals as skill trainers

Quality and quantity of teaching multiplied by technological applications in education

Funding to create conditions of future life as well as to provide for solutions to present problems

Production according to current and future needs of the handicapped as determined by needs assessment

Instructional materials (and media) purchased only on basis of demonstrated effectiveness and efficiency factors

Research in learning theory and teaching techniques which is consumer product oriented 
trained adult in charge of this activity. Another nearby room may be arranged for individual presentations of pre-academic and academic learning tasks, such as discrimination of colors, sizes, and shapes. And so on. The combinations and permutations are endless, and exciting.

This kind of training/learning arrangement calls for new skills for old administrators. The techniques of systems analysis are invaluable in planning, organizing, and evaluating such an undertaking. This means that systems managers may be more appropriate than principals; that systems supervisors may be more appropriate than teachers; and that skill trainers may be more appropriate than teacheraides. The consoling thought is, however, that such a system can be wholly accountable, data-based accountable, for the only mission that education has ever had-socially appropriate behavior change.

\section{CONCLUSION}

All this has vast implications for teaching training. New skills for a new age will have to be learned and mastered by all of us in higher education if we do not wish to become outmoded and valueless in a world that no longer recognizes intrinsic value in college degrees and teaching certificates. In spite of powerful traditions and enormous bureaucracies, we must master Post-Industrial Age technology and put it to use to build new, relevant, efficient, and humane educational models. In the not distant future, the term teacher will have to have a very different connotation-one that carries the meaning and respect that it did in ages past.

\section{REFERENCES}

Barnes, R. Toward alternative futures. Topeka, KS: The Menninger Foundation, 1974.

Butler, F. C. Instructional systems development for vocational and technical training. Englewood Cliffs, NJ: Educational Technology Publications, 1972.

Commission on Instructional Technology. To improve learning. Washington, DC: Government Printing Office, 1970.

Comptroller General of the United States. Report to Congress: Educational laboratory and research and development center programs need to be strengthened. Washington, DC: General Accounting Office, 1973.

Conley, R. W. The economics of mental retardation. Baltimore: Johns Hopkins University Press, 1973.

Del Turco, R. Circuit training for the mentally retarded. A paper prepared for course requirement in Special Problems, Adams State College, Alamosa, Colorado, 1971.

Drucker, P. F. The age of discontinuity: Guidelines to our changing society. New York: Harper \& Row, 1968.
Drucker, P. F. Management: Tasks, responsibilities, practices. New York: Harper \& Row, 1974.

EPIEGRAM. Educational Products Information Exchange Institute, 1975, 3(8).

Gold, M. W. Classroom techniques. Education and Training of the Mentally Retarded, 1968, 3, 31-37

Lent, J. R. Developing daily-living skills for the mentally retarded. In J. M. Kauffman \& J. S. Payne (Eds.), Mental retardation: Introduction and personal perspectives. Columbus, $\mathrm{OH}$ : Charles E. Merrill, 1975.

Lippman, L. \& Goldberg, I. I. Right to education: Anatomy of the Pennsylvania case and its implications for exceptional children. New York: Teachers College Press, Columbia University, 1973.

\section{ADDITIONAL READINGS}

Lent, J. R. Mimosa Cottage: Experiment in hope. Psychology Today, 1968, 2(1), 51-58.

Lent, J. R., LeBlanc, J., \& Spradlin, J. E. Designing a rehabilitative culture for moderately retarded adolescent girls. In $R$. Ulrich, $T$. Stachnik, \& J. Mabry (Eds.), Control of human behavior: From cure to prevention, Vol. 2. Glenview, IL: Scott, Foresman \& Co., 1970.

Lent, J. R. \& McLean, B. M. The trainable retarded: The technology of teaching. In N. G. Haring \& R. L. Schiefelbusch (Eds.), Teaching special children. New York: McGraw-Hill, in press.

Mann, L. \& Sabatino, D.A. (Eds.). The second review of special education. Philadelphia: JSE Press, 1974.

Zigler, E. The future of social policy for children. Fifth in the series, Notes from the Center. Syracuse, NY: Center on Human Policy, Syracuse University, 1973.

\section{ALERT}

The Council for Exceptional Children's 53rd Annual International Convention will be held in Los Angeles April 20-25. Co-headquarter hotels will be the Biltmore and the Los Angeles Hilton. For more information, contact:

The Council for Exceptional Children

1920 Association Drive

Reston, Virginia 22091

On August 13-17, the Scandinavian Summer Seminars 1975 are presenting a topic of special interest-"Special Education in Scandinavia." This seminar and the nine others on the program will be conducted in English. For further information, contact:

Det Danske Selskab

2, Kultorvet, DK-1175

Copenhagen $\mathrm{K}$ 
CLASSROOM FORUM

\author{
Edited by Alwyn H. Holloway \\ Center Coordinator, South DeKalb Children's \\ Center-Severely Disturbed
}

I am a special help resource teacher in a school where resource programs are just being started. I am finding it difficult to work with some of the regular classroom teachers because of resistance and resentment of the program. Can you give me some suggestions as to how I might diminish some of the resistance and encourage interest and cooperation?

The dilemma you are faced with is by no means unique to your specific school. Though I am certain that you find many of the regular classroom teachers supportive and interested, there will usually be a few who will be somewhat apprehensive of you and the services you have to offer. This resistance can be due to many things and often not because of you personally. The staff might not really understand what services you have to offer. There might also be resentment because of the freedom you have to serve many different children in many different ways. You also are able to help children in small numbers and with a lot of different types of equipment. Because of your role as a resource to teachers as well as to children, much of your effectiveness depends on the interest and receptiveness of the staff. Therefore, it is essential that resistance to your program be kept to a minimum. Doing this is easier said than done and cannot be accomplished overnight. If you can be patient and supportive and utilize some of the suggestions given below, perhaps you will have success being a resource to both teachers and students.

1. Hold an inservice for teachers and principal. Because your program is a new addition to previous school services, many teachers do not actually know what your program involves and what your goals are. The inservice, therefore, would involve a demonstration and discussion of what you hope to accomplish. This would be an excellent opportunity to ask teachers for suggestions as to where they feel you might be able to help them.

2. Invite teachers to come and observe their children when you have them in individual and/or in small group sessions. This provides an excellent chance to ask questions and to observe materials and methods.

3. When teachers ask for help for a child, go to them rather than asking them to meet you in the resource room. Meet them at a time convenient to them. Make yourself available!

4. When a teacher asks for help with a particular child, you might suggest an observation of the child. Let the teacher know that you will be observing the child, not the teacher. After the observation, it is imperative that the teacher be given some positive reinforcement and feedback as to the child's behavior and to the classroom situation. Suggestions can be made as to possible materials and techniques for use with that specific child. Involve the teacher as much as possible in programming so that she will feel more responsibility for the plan and will be willing to implement it. Let the teacher know that, although you don't always know the most effective methods initially, through programming and reprogramming the two of you can devise a workable, effective plan.

5. Be willing to loan materials and to demonstrate them. A discussion of objectives of such materials would be very helpful.

6. Be an active, integral member of the school staff. Take duties, volunteer for committees, participate in PTA and other extra curricular activities of the school.

7. Enthusiasm is contagious! Take time to share successes as well as failures with teachers and principal. Be equally enthusiastic about what others are doing.

8. Be positive in your relationships with the teachers-a behavior modification program, if you wish. Consistent encouragement and cooperation are a must if children are to receive everyone's best.

Thanks to Ms. Rhonda Gottlied, Special Help Teacher, and Ms. Sandra Sue Harwell, Speech Therapist, for their input. 